\title{
New ornamental cultivars of Bird cherry for northern region with severe climate
}

\author{
Anna Lokteva ${ }^{1}$, and Vladimir Simagin ${ }^{1 *}$ \\ ${ }^{1}$ Central Siberian botanical garden of SB RAN, 630090, Novosibirsk, Russia
}

\begin{abstract}
Bird cherry is a highly winter-hardy tree that successfully grows in the boreal zone of Eurasia. It can be successfully used here in landscaping, but highly decorative varieties have not yet been created. Using genotypes of bird cherry and choke cherry with rare signs of leaves and flowers in the selection of genotypes made it possible to obtain a number of new highly decorative easily propagating varieties that are well adapted to local conditions with an original set of characters that are promising for decorative landscaping in the northern zone.
\end{abstract}

\section{Introduction}

In the decorative landscaping of Siberia and regions similar to it in severity of climate, a small composition of woody and shrubby plants is used. The introduction of tree species and shrubs that arose in a milder climate and selectively created on their basis is most often unsuccessful here because of their insufficient winter hardiness. Therefore, the use of the genetic resources of native species for this zone, the apportionment of genotypes with original decorative qualities inside them and the creation of varieties based on them that are well adapted to local conditions is undoubtedly an urgent task.

Species of the subgenus Padus of the genus Prunus L. grow in a various of climatic and environmental conditions. The most valuable for our zone is the common bird cherry Prunus padus L., which grows in the boreal and forest-steppe zones of northern Eurasia, as well as its mountain systems [1], and the North American choke cherry - Prunus virginiana L., growing in similar zones of North America [2]. This species has been successfully introduced in the European part of Russia and Western Siberia.

Bird cherry has the highest frost resistance among representatives of the Plum genus. It grows with a medium-sized tree in moderately humid habitats, spreads in nature by seeds and the growth of fallen branches, and blooms early. Virginia choke cherry grows in drier habitats in the form of a high shrub, spreads by seeds and basal shoots, has more multiflowered dense and shorter clusters. It blooms 10-15 days later. It has been experimentally shown that these species hybridize easily, highly forming winter-hardy, abundantly flowering trees in intermediate periods, easily propagating vegetatively [3, 4].

The study of the intraspecific diversity of these species showed that they have significant variability in the size of the clusters and flowers, the size and shape of the crown, and the timing of flowering $[5,6]$. Occasionally, original mutations occur in the

\footnotetext{
* Corresponding author: simagin48@mail.ru
} 
color of leaves and flowers $[7,8,9]$. The use of such genetic sources makes it possible to obtain highly decorative plants that differ markedly from the species background and increase the possibilities of growing highly decorative trees in the northern regions [10].

\section{Material and methods}

Crossings were carried out at the collection of subgenus Padus of the Laboratory for the introduction of food plants of the Central Siberian botanical garden of the SB RAS. Flowers were isolated at the stage of loose buds, pollination was carried out without castration of flowers. Hybrid seeds were planted in the nursery, Then whence at 2-3 years of age it growing at selection plots. Description of flowers and clusters make out for 2-3 years of flowering. In the same season, prominent seedlings studied rooting by green cuttings.

\section{Results and discussion}

The first series of ornamental hybrids was obtained by pollination of a large-flowered specimen, № 1-1-8, with pollen from American cultivar of P. virginiana Schubert, from the collection of KOSS VIR. Thouse hybrids have white flowers, their leaves change color in the middle of summer from green to purple, and they differ in growth strength and crown shape (Patents № 5554 - Purple Candle; № 5555 - Siberian Beauty; № 5553 - Red Tent). For further crossings, in addition to these sources, the pink-flowered variety Tenderness and the Colorata cultivar with intensive dark staining of young leaves and flowers, as well as local large-flowered forms of bird cherry were used. Of the obtained selection material, 6 new ornamental cultivars were registered.

Cultivar Cloud (patent № 8742). Seedling from free pollination № 1-1-8. The tree is medium-sized, 4-5 m high with an oval crown. The buds are white, the flowers are large, white, with wide petals, the diameter of the flowers is $25-26 \mathrm{~mm}$. Clusters $13-14 \mathrm{~cm}$ long, about $30 \mathrm{~mm}$ in diameter, fairly dense. Flowering early, plentiful. The leaves are medium sized, with a usual green color, yellowing in autumn. Like other varieties, it propagates well by green cuttings.

Variety Slender (patent № 8741, Fig. 1A). Seedling from crossing cultivars Purple candle and Tenderness. Tall tree $(7-8 \mathrm{~m})$ with a narrow pyramidal crown. The leaves are large, initially green, from mid-summer purple. The buds are pink, the flowers are soft pink, small, with a diameter of 15-16 mm, clusters $16-17 \mathrm{~cm}$ long, with a diameter of about 25 $\mathrm{mm}$. Flowering is medium early, plentiful. Well propagated by green cuttings.

Cultivar Red season (patent № 8740, Fig. 1B). Seedling from crossing varieties Purple candle and Colorata. A low tree (3-4 m) with a spreading crown. The leaves are not large. Intensively red in spring, then gradually turn green, but burgundy streaks remain. By the end of summer, the leaves turn purple. The flowers are lilac-pink, with wide petals, with a diameter of about $16 \mathrm{~mm}$, Clusters $14-15 \mathrm{~cm}$ long, with a diameter of about $22 \mathrm{~mm}$. Flowering early, plentiful. It is well rooted in green cuttings.

Cultivar Ruddy cheeks (patent № 10081, Fig. 2A). The seedling of grade Tenderness. Low tree (4-5 m) with a wide oval crown. Leaves are green, medium in size. The flowers are of the original cup-shaped, soft pink, with wide petals, a diameter is about $20 \mathrm{~mm}$. Clusters $16-17 \mathrm{~cm}$ long, about $25 \mathrm{~mm}$ in diameter. Flowering is medium early, plentiful. It is well rooted in green cuttings.

Cultivar Pink Dream (patent № 10089). Seedling from crossing cultivars Closely clusters and Colorata. A sprawling tree 3-3.5 m high. Blossoming young leaves are bright red, then green, with burgundy veins. In autumn, the leaves turn yellow. Flowers with a diameter of 15-16 mm, with wide petals, lilac-pink, on very short pedicels. The clusters are 
dense, narrow, 13-14 $\mathrm{cm}$ long, about $14 \mathrm{~mm}$ in diameter. Flowering is medium early, plentiful. It is well rooted in green cuttings.

Cultivar Bellflower (patent № 10082, Fig. 2B). Seedling bird cherry hybrid of unknown origin. A tree 4-5 m high with a narrowly pyramidal crown. The leaves are green, the flowers are white, the original bell-shaped, the petals are wide. The diameter of the flower is about $16 \mathrm{~mm}$. Multi-flowered clusters, $18-20 \mathrm{~cm}$ long, with a diameter of about $25 \mathrm{~mm}$. Flowering in medium terms, plentiful. It is well rooted in green cuttings.
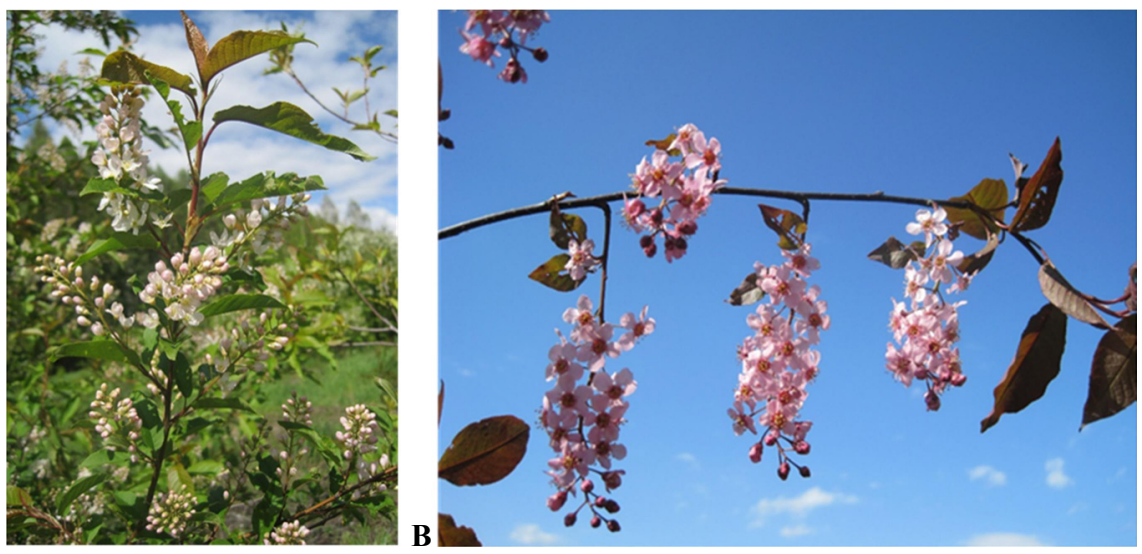

Fig. 1. The ornamental cultivars of Bird cherry: A - Variety 'Slender,'B - 'Red season`

A
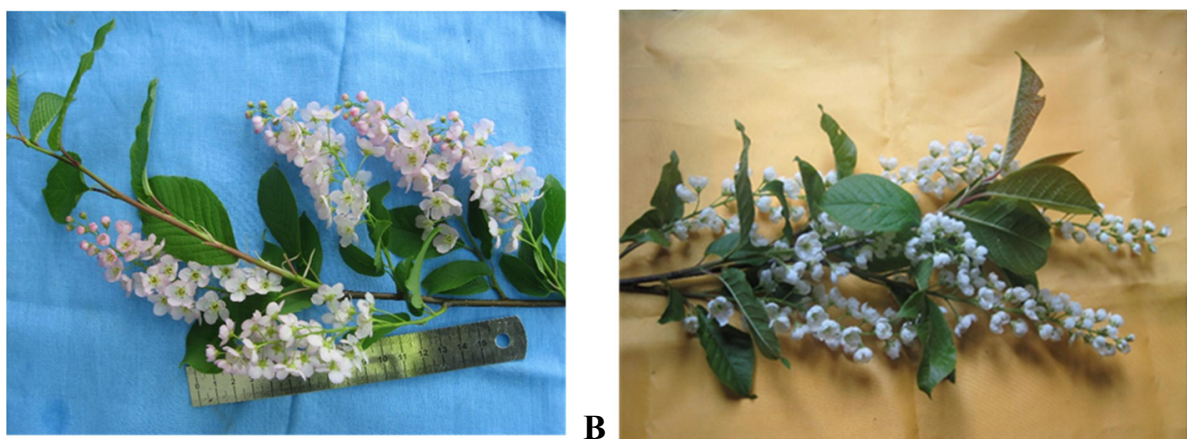

Fig. 2. The ornamental cultivars of Bird cherry: A - 'Ruddy cheeks', B - 'Bellflower'

This work was supported by the state project number: AAAA-A17-117012610054-6 for the Central Siberian Botanical Garden (CSBG) SB RAS). Materials of the bioresource scientific collection of the CSBG SB RAS "Collections of living plants in open and closed ground", USU No. 440534 were used.

\section{References}

1. G.V. Eremin, Systematics of stone fruit plants, in Pomology (VNII SPK Press, Orel, 2008)

2. R.G. St. Pierre, The Chokecherry (Saskatchewan University Press, Saskatchewan, 1993) 
3. V.S. Simagin, Peculiarities of flowering biology and crosspollination of Prunus padus, Prunus virginiana and their hybrids, in Collected paper Problems of reproductive biology (Perm, 1996)

4. V.S. Simagin, Results of interspecific hybridization of cherry and bird cherry in Novosibirsk, in Collected papers Problems of apomixis and interspecific hybridization (Science Press, Siberian branch of RAS, Novosibirsk, 1987)

5. V. S. Simagin, G.V. Eremin, About the Biodiversity of Bird cherry at Euroasia, Flora and vegetation of Altay, Proceeding of South -Siberian bot. gard, 4,1 (1999)

6. A.V. Lokteva, Polymorphism of bird cherry at Western Siberia south as form source to introduction and analitic selection, Avtoref. Candidate's Diss. in Biology (Novosibirsk, 2009)

7. A.V. Lokteva, V.S. Simagin, Siberian Herald of Agricultural Science, 6 (2010)

8. W.J. Bean, Trees and shrubs hardy in British Isles. (St. Martin Press, London, 1987)

9. G. Krussman, Manual of Cultivated Broad-leaved Trees and Shrubs (Timber Press, London, 1986)

10. A.V. Lokteva, V.S. Simagin, Herald of Altay GAU, 6 (2010) 